\title{
Secukinumab in Active Rheumatoid Arthritis after Anti-TNF $\alpha$ Therapy: A Randomized, Double-Blind Placebo-Controlled Phase 3 Study
}

\author{
Hasan Tahir (D) Atul Deodhar · Mark Genovese - Tsutomu Takeuchi • \\ Jacob Aelion · Filip Van den Bosch · Sibylle Haemmerle · Hanno B. Richards
}

Received: July 12, 2017 / Published online: November 14, 2017

(C) The Author(s) 2017. This article is an open access publication

\begin{abstract}
Introduction: 'REASSURE' (NCT01377012), a phase 3 study, evaluated the efficacy and safety of secukinumab in patients with active rheumatoid arthritis (RA) who had an

Enhanced content To view enhanced content for this article go to http://www.medengine.com/Redeem/ 05CCF06063A967B6.
\end{abstract}

Electronic supplementary material The online version of this article (doi:10.1007/s40744-017-0086-y) contains supplementary material, which is available to authorized users.

H. Tahir $(\bowtie)$

Barts Health NHS Trust, London, UK

e-mail: hasan.tahir@bartshealth.nhs.uk

A. Deodhar

Oregon Health and Science University, Portland, OR, USA

M. Genovese

Stanford University, Stanford, CA, USA

T. Takeuchi

Keio University School of Medicine, Tokyo, Japan

J. Aelion

West Tennessee Research Institute, Jackson, TN, USA

F. Van den Bosch

Ghent University Hospital, Ghent, Belgium

S. Haemmerle $\cdot$ H. B. Richards

Novartis Pharma AG, Basel, Switzerland inadequate response to, or intolerance of, tumor necrosis factor inhibitors (TNF-inhibitors).

Methods: A total of 637 patients were randomized (1:1:1) to receive intravenous secukinumab $10 \mathrm{mg} / \mathrm{kg}$ (baseline, weeks 2 and 4 ) followed by subcutaneous secukinumab $150 \mathrm{mg}$ or $75 \mathrm{mg}$ every 4 weeks (starting from week 8) or placebo at the same dosing schedule. The primary endpoint was the American College of Rheumatology 20\% improvement criteria (ACR20) at week 24. Other predefined hierarchical endpoints included Health Assessment Questionnaire-Disability Index, van der Heijde modified total Sharp score (vdH-mTSS) at week 24, and major clinical response (MCR; continuous 6 month period of ACR70 response) at 1 year.

Results: The primary efficacy endpoint was met with both secukinumab dose groups: ACR20 response rate at week 24 was $35.2 \%$ for both secukinumab dose groups $(P=0.0009)$ vs $19.6 \%$ for placebo. The improvements in secondary endpoints were greater in the secukinumab dose groups vs placebo but did not meet statistical significance. The overall safety profile was similar across all treatment groups.

Conclusion: Secukinumab demonstrated efficacy in reducing disease activity over placebo as measured by ACR20 in patients with active RA who had an inadequate response to TNF-inhibitors. Secukinumab demonstrated a safety profile similar to other biologics currently approved for RA. 
Funding: Novartis Pharma AG.

Trial registration: ClinicalTrials.gov identifier: NCT01377012.

Keywords: ACR; Autoimmune; Biologic; Clinical trial; HAQ-DI; IL-17A; Randomized; Rheumatoid arthritis; Secukinumab; vdH-mTSS

\section{INTRODUCTION}

Rheumatoid arthritis (RA) is a chronic, inflammatory, systemic autoimmune disease characterized by symmetric synovitis leading to cartilage damage and joint destruction, which may also be complicated by numerous extra-articular manifestations [1]. Current treatment for RA with traditional disease modifying anti-rheumatic drugs (DMARDs) is often inadequate as these drugs only partially control established disease, and have many adverse effects that limit their use [2]. While tumor necrosis factor inhibitors (TNF-inhibitors) are the first line biologics used in DMARD failure patients, $30-40 \%$ of patients with established disease fail to respond to them [2]. Further, many of those who do initially respond do not go on to achieve complete remission or lose response over time [2]. Biologics targeting other disease driving mechanisms, such as co-stimulatory modulators with Cytotoxic $\mathrm{T}$ lymphocyte-associated antigen 4 Ig (CTLA-4-immunoglobulin), B cell depletion as well as interleukin (IL)- 6 receptor blockers, are approved for use in patients for whom TNF-inhibitor therapy has failed [3-5].

IL-17A, the key pro-inflammatory cytokine in the TH17 pathway, is recognized as a key cytokine in autoimmunity [6]. While its role in the pathogenesis of RA is not yet fully understood, it has been suggested that it plays a pivotal role in both the inflammatory and destructive joint tissue manifestations of RA [7-9]. Secukinumab (AIN457), a fully human monoclonal antibody that neutralizes the activity of IL-17A, [6] has demonstrated efficacy in moderate-to-severe psoriasis, psoriatic arthritis (PsA) and ankylosing spondylitis (AS) $[1,10-14]$.
While secukinumab displayed some efficacy in RA in several phase II trials, the small size of the trials did not allow for definitive conclusions on the role of IL-17A blockade in RA to be made [15-18]. Subsequently, three phase 3 studies of secukinumab in RA were initiated; two assessed the efficacy and safety of secukinumab in comparison with placebo, and the third compared secukinumab with both placebo and the active comparator abatacept [19]. Here, we report, from the phase 3 REASSURE study, efficacy at week 24 compared with placebo, as well as the longer term safety of secukinumab in patients with RA who had an inadequate response to, or intolerance of, TNF-inhibitors.

\section{METHODS}

\section{Study Design}

This phase 3 study (ClinicalTrials.gov identifier, NCT01377012) used a double-blind, randomized, parallel-group, placebo-controlled design to assess the efficacy and safety of secukinumab in patients with active RA who had an inadequate response to, or intolerance of, TNF-inhibitors. It included 139 centers in 15 countries. The core study was conducted over 2 years and the extension was planned to be conducted for 3 years, however, due to early termination of the secukinumab RA program, patients remaining in the trial at the time of termination were discontinued.

After a 4-week screening period, patients were randomly assigned $(1: 1: 1)$ to receive intravenous (i.v.) secukinumab $10 \mathrm{mg} / \mathrm{kg}$ (baseline, weeks 2 and 4 ) followed by subcutaneous (s.c.) secukinumab $150 \mathrm{mg}$ or $75 \mathrm{mg}$ every 4 weeks (starting at week 8) up to week 48 , or placebo on the same i.v. and s.c. dosing schedule (Fig. 1).

At week 16, patients on placebo who were non-responders (response was defined as $\geq 20 \%$ improvement from baseline in both tender and swollen joint counts) were re-randomized (1:1) to receive s.c. secukinumab $150 \mathrm{mg}$ (placebo-secukinumab $150 \mathrm{mg}$ ) or $75 \mathrm{mg}$ (placebo-secukinumab $75 \mathrm{mg}$ ) every 4 weeks. 

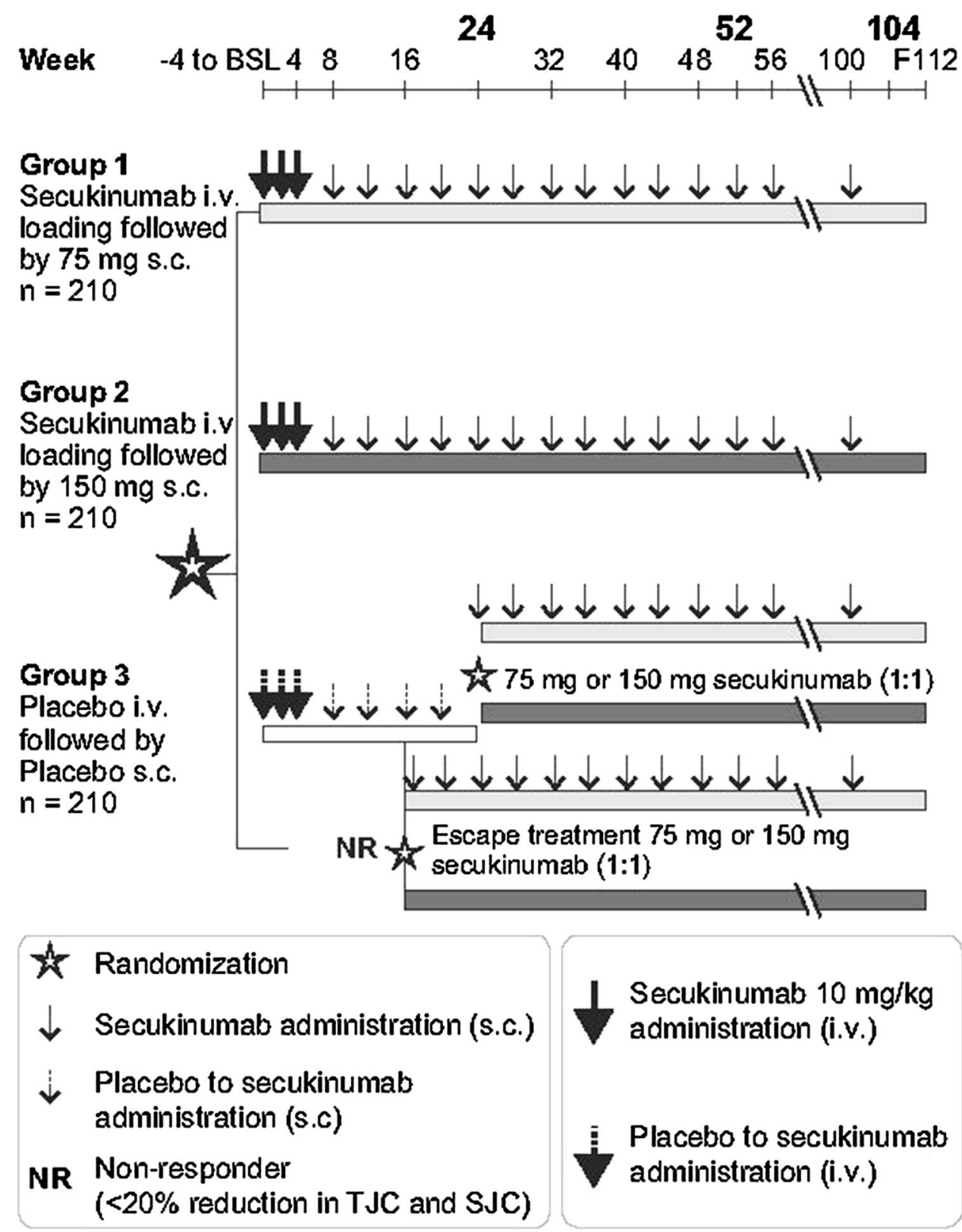

$B S L=$ baseline; i.v.= intravenous $(l y) ; N R=$ non-responder;

s.c. = subcutaneous $(l y) ; S J C=$ Swollen Joint Count;

$\mathrm{TJC}=$ Tender Joint Count

Fig. 1 Study design

Patients who were placebo responders at week 16 continued to receive placebo until week 24 , when they were randomized (1:1) to s.c. secukinumab 150 or $75 \mathrm{mg}$ every 4 weeks. Rescue medication was not allowed until week 24 .
However, patients who were deemed to be not benefiting from the study drug by the investigator, or for any reason on their own accord, were free to discontinue participation in the study at any time. Patients who completed the 
2 year core study were eligible to enter the open-label extension study, where all patients received s.c. secukinumab $150 \mathrm{mg}$ every 4 weeks.

Primary and secondary efficacy data are presented for the core study (placebo-controlled up to week 24) up to week 52. Additionally, longer-term (104-week) efficacy data are presented. Safety data are presented for the initial 16-week period, as well as for the entire study including the extension, up to last patient last visit (LPLV).

\section{Patients}

Patients aged at least 18 years who had been diagnosed with RA at least 3 months before screening, and classified using the ACR 2010 classification criteria were eligible for the study. Patients were required to have active disease at baseline, defined by $\geq 6 / 68$ tender joints and $\geq 6 / 66$ swollen joints, and be positive for either rheumatoid factor or anti-cyclic citrullinated peptides (CCP) antibodies, in combination with high-sensitivity C-reactive protein (hsCRP) $\geq 10 \mathrm{mg} / \mathrm{L}$ or erythrocyte sedimentation rate $(\mathrm{ESR}) \geq 28 \mathrm{~mm} / \mathrm{h}$.

Patients had to have been on at least one TNF-inhibitor for at least 3 months before randomization and have experienced an inadequate response or intolerance. Patients should also have received methotrexate for at least 3 months, and be on a stable dose for at least 4 weeks, before randomization. Patients taking systemic corticosteroids or NSAIDs had to be on a stable dose for at least 4 weeks before randomization. Patients who had been taking DMARDs other than methotrexate (MTX), or were on a TNF-inhibitor, underwent an appropriate wash-out period prior to randomization.

The major exclusion criteria included RA patients having functional status class IV according to the ACR 1991 revised criteria, ongoing rheumatic or inflammatory joint diseases other than RA, evidence of malignancy or infection seen on chest X-ray, active tuberculosis infection, previous use of biologic immunomodulating agents except TNF-inhibitors, or previous exposure to secukinumab or other biologic drugs targeting IL-17.
The study was conducted in accordance with the Declaration of Helsinki, and was approved by the institutional review boards or independent ethics committees. Written informed consent was provided by all enrolled patients.

\section{Outcomes}

The primary objective was to demonstrate that the efficacy of secukinumab 150 or $75 \mathrm{mg}$ at week 24 was superior to placebo, based on the proportion of patients achieving the American College of Rheumatology 20\% improvement criteria (ACR20 response).

Secondary objectives included in the pre-defined hierarchical testing strategy were to demonstrate superiority of secukinumab $150 \mathrm{mg}$ or $75 \mathrm{mg}$ over placebo in terms of change from baseline in the Health Assessment Questionnaire-Disability Index (HAQ-DI), van der Heijde modified total Sharp score (vdH-mTSS) at week 24 (pooled for both secukinumab dose regimens), and achieving a continuous six-month period of ACR70 response (major clinical response; MCR) at week 52.

Additional secondary efficacy endpoints included change from baseline in joint/bone damage (radiographic score), erosion and joint space narrowing, ACR20/50/70 and EULAR responses, as well as Disease Activity Score 28 (DAS28), DAS28 remission (DAS28 $<2.6)$ and low disease activity (DAS28 $\leq 3.2$, using hsCRP), vs placebo, over time up to week 104 .

Safety was assessed throughout the core and extension periods. All treatment emergent adverse events (TEAEs), serious AEs (SAEs), laboratory evaluations, immunogenicity (anti-secukinumab antibodies) were evaluated.

\section{Statistical Analysis}

Sample size calculations were performed using Fisher's exact test; as two secukinumab regimens were tested against placebo with respect to the primary endpoint (ACR20 response at week 24), the type-I-error was split to $2.5 \%$ two-sided for each comparison.

With 210 patients randomized to each treatment group, this trial had 
approximately $>99 \%$ power to detect between-group differences in the primary endpoint, and was also sufficiently powered to detect between-group differences in the secondary endpoints, such as changes from baseline to week 24 in HAQ-DI (>99\% power) and van der Heijde modified total Sharp score (68\%), and MCR at week 52 (88\%).

In terms of minimum sample sizes, for $90 \%$ power, and assuming a response rate of $20 \%$ in the placebo regimen, at least 70 patients per regimen were needed to show a response rate of $50 \%$ in the secukinumab regimens.

Analyses of efficacy variables were performed on all patients who were randomized and to whom study treatment had been assigned (full analysis set, FAS). The primary endpoint of ACR20 at week 24 was analyzed via logistic regression with treatment as a factor and baseline body weight as a covariate. Odds ratios and 95\% CIs were presented comparing each secukinumab regimen to placebo. Continuous variables (e.g. ACR components, HAQ-DI, etc.) were analyzed using a mixed-effects repeated measures model (MMRM). As such, single-point imputation of missing data was not performed. A predefined hierarchical test was used to protect the family-wise type I error rate at 5\% across the primary and the ranked secondary endpoints.

In general, for binary endpoints, data missing due to patients meeting the criteria for early escape at week 16 was handled as non-responders. This was done for all treatment regimens in order to minimize bias. For continuous endpoints, data collected after the patient switched to secukinumab was treated as missing for placebo patients and was analyzed using a mixed-effects repeated measures model (MMRM), which is valid under the missing at random (MAR) assumption. For secukinumab patients, the actual values were used in the analysis.

Analyses of safety endpoints were performed on all patients who received at least one dose of the study drug during the treatment period (safety set). Patients were evaluated according to treatment received. As appropriate, the incidence of AEs was presented per 100 patient years of exposure.

\section{RESULTS}

\section{Patients}

In total, 637 patients were randomized to secukinumab $150 \mathrm{mg}(n=213)$, secukinumab $75 \mathrm{mg}(n=210)$ or placebo $(n=214)$. This study and its extension were discontinued early, due to initial results from the direct comparison with abatacept [19] suggesting no additional benefit to RA patients with inadequate response to TNF-inhibitors. Overall, 237 (37.2\%) patients completed 104 weeks of treatment: 81 (38.0\% of those randomized) in the secukinumab $150 \mathrm{mg}$ group, 76 (36.2\% of those randomized) in the secukinumab $75 \mathrm{mg}$ group, and 80 (37.4\% of those randomized) in the placebo group (supplementary Fig. S1). Of these, 196 (82.7\%) entered the extension study and were treated with s.c. secukinumab $150 \mathrm{mg}$ (only dose studied in extension). The main reason for discontinuation other than study termination was lack of efficacy (106 patients), followed by subject decision (56 patients). The maximum exposure time for any secukinumab dose in the study, including the extension study, was 184 weeks, with a mean exposure of $604(\mathrm{SD} \pm 341.23)$ days, and a median exposure of 588 days.

Of the 214 patients randomized to placebo, 190 remained on the study at week 16 . Of these, 110 were non-responders at week 16, and 109 of these were randomized to secukinumab $150 \mathrm{mg}$ $(n=53)$ or secukinumab $75 \mathrm{mg}(n=56)$. Of the 80 placebo responders at week 16, 72 were randomized at week 24 to secukinumab $150 \mathrm{mg}$ $(n=34)$ or secukinumab $75 \mathrm{mg}(n=38)$.

Patient demographics and baseline characteristics were comparable across the treatment groups (Table 1). Most patients ( $\geq 80 \%$ in each treatment group) were $<65$ years of age, with median age ranging from 53.0 (placebo group) to 54.0 years (both secukinumab treatment groups). The majority of patients were female (range $85.0-88.6 \%$ in all treatment groups), were of Caucasian (range 38.6-41.8\%) or Asian (range 31.0-36.7\%) origin and weighed $<90 \mathrm{~kg}$ (range $85.5-86.7 \%$ ). The mean BMI was approximately $27 \mathrm{~kg} / \mathrm{m}^{2}$ across all treatment groups. 
Table 1 Demographics and baseline characteristics

\begin{tabular}{|c|c|c|c|}
\hline Characteristic & $\begin{array}{l}\text { Secukinumab } 150 \mathrm{mg} \\
(n=213)\end{array}$ & $\begin{array}{l}\text { Secukinumab } 75 \mathrm{mg} \\
(n=210)\end{array}$ & $\begin{array}{l}\text { Placebo } \\
(n=214)\end{array}$ \\
\hline Age (years), mean (SD) & $53.2(11.6)$ & $53.3(12.3)$ & $52.2(11.6)$ \\
\hline Female, $n(\%)$ & $188(88.3)$ & $186(88.6)$ & $182(85.0)$ \\
\hline Weight (kg), mean (SD) & $67.6(20.0)$ & $67.5(18.9)$ & $69.1(19.8)$ \\
\hline \multicolumn{4}{|l|}{ Race, $n(\%)$} \\
\hline Caucasian & $89(41.8)$ & $81(38.6)$ & $84(39.3)$ \\
\hline Black & $12(5.6)$ & $10(4.8)$ & $7(3.3)$ \\
\hline Asian & $66(31.0)$ & $77(36.7)$ & $74(34.6)$ \\
\hline Native American & $34(16.0)$ & $30(14.3)$ & $40(18.7)$ \\
\hline Other & $12(5.6)$ & $11(5.2)$ & $9(4.2)$ \\
\hline Unknown & $0(0.0)$ & $1(0.5)$ & $0(0.0)$ \\
\hline Tender 68-joint count, mean (SD) & $26.6(16.2)$ & $26.6(15.6)$ & $24.7(15.8)$ \\
\hline Swollen 66-joint count, mean (SD) & $17.1(11.0)$ & $17.2(10.9)$ & $16.4(11.3)$ \\
\hline Duration of RA (years), mean (SD) & $9.0(8.0)$ & $8.4(8.0)$ & $7.8(8.0)$ \\
\hline HAQ-DI, mean (SD) & $1.7(0.7)$ & $1.7(0.6)$ & $1.7(0.6)$ \\
\hline Total vdH-mTSS score, mean (SD) & $48.1(51.8)$ & $55.0(55.3)$ & $57.7(66.8)$ \\
\hline DAS28-CRP & $4.9(0.9)$ & $4.9(0.9)$ & $4.8(0.8)$ \\
\hline DAS-28-ESR & $5.7(0.9)$ & $5.7(0.8)$ & $5.6(0.8)$ \\
\hline Positive for $\mathrm{RF}^{\mathrm{a}}, n(\%)$ & $200(93.9)$ & $191(91.0)$ & $200(93.5)$ \\
\hline Positive for anti-CCP antibodies, $n(\%)$ & $194(91.1)$ & $189(90.0)$ & $194(90.7)$ \\
\hline TNF-naïve patients, $n(\%)$ & $1(0.5)$ & $9(4.3)$ & $5(2.3)$ \\
\hline $\begin{array}{l}\text { Prior use of other biologic DMARD, } \\
n(\%)^{\mathrm{b}}\end{array}$ & $1(0.5)$ & $0(0.0)$ & $1(0.5)$ \\
\hline \multicolumn{4}{|c|}{ Use of oral DMARDs at randomization, $n(\%)$} \\
\hline Methotrexate & $208(97.7)$ & $208(99.0)$ & $210(98.1)$ \\
\hline Leflunomide & $1(0.5)$ & $0(0)$ & $1(0.5)$ \\
\hline Other $^{c}$ & $6(2.8)$ & $9(4.3)$ & $15(7.0)$ \\
\hline Systemic glucocorticoids use, $n$ (\%) & $124(58.2)$ & $130(61.9)$ & $126(58.9)$ \\
\hline
\end{tabular}

DAS28 Disease Activity Score in 28 joints, DMARD disease-modifying anti-rheumatic drug, ESR erythrocyte sedimentation rate, $H A Q-D I$ Health Assessment Questionnaire-Disability Index, $I V$ intravenous, $S D$ standard deviation, $v d H-m T S S$ van der Heijde modified total Sharp score, $R A$ rheumatoid arthritis, $R F$ rheumatoid factor, $T N F$ tumor necrosis factor

a Negative was defined as RF $<14 \mathrm{U} / \mathrm{mL}$

b Other than TNF-alpha inhibitors

c Other than MTX and Leflunomide 
Table 2 Summary of primary and secondary endpoints at weeks 24, 52 and 104

\begin{tabular}{|c|c|c|c|c|}
\hline $\begin{array}{l}\text { Endpoint, } n(\%) \text { unless } \\
\text { stated }\end{array}$ & Week & $\begin{array}{l}\text { Secukinumab } 150 \mathrm{mg} \\
(n=213)\end{array}$ & $\begin{array}{l}\text { Secukinumab } 75 \mathrm{mg} \\
(n=210)\end{array}$ & $\begin{array}{l}\text { Placebo } \\
(n=214)\end{array}$ \\
\hline \multirow[t]{3}{*}{$\mathrm{ACR} 20^{\mathrm{a}}$} & 24 & $75(35.2)^{*}$ & $74(35.2)^{*}$ & $42(19.6)$ \\
\hline & 52 & $88(61.5)$ & $75(57.7)$ & N/A \\
\hline & 104 & $50(69.4)$ & $50(74.6)$ & N/A \\
\hline \multirow[t]{3}{*}{$\mathrm{ACR} 50^{\mathrm{a}}$} & 24 & $34(16.0)^{*}$ & $37(17.6)^{*}$ & $14(6.5)$ \\
\hline & 52 & $36(27.7)$ & $34(23.8)$ & N/A \\
\hline & 104 & $28(38.9)$ & $25(37.3)$ & N/A \\
\hline \multirow[t]{3}{*}{ ACR7 $70^{a}$} & 24 & $8(3.8)$ & $17(8.1)^{*}$ & $5(2.3)$ \\
\hline & 52 & $14(9.8)$ & $13(10.0)$ & N/A \\
\hline & 104 & $12(16.7)$ & $9(13.4)$ & N/A \\
\hline \multirow[t]{3}{*}{ HAQ-DI ${ }^{\mathrm{b}}$} & 24 & $-0.4(0.0)$ & $-0.4(0.0)$ & $-0.2(0.1)$ \\
\hline & 52 & $-0.4(0.6)$ & $-0.4(0.6)$ & N/A \\
\hline & 104 & $-0.5(0.7)$ & $-0.5(0.7)$ & $\mathrm{N} / \mathrm{A}$ \\
\hline
\end{tabular}

$A C R$ American College of Rheumatology, CRP C-reactive protein, DAS28 disease activity score in 28 joints, ESR erythrocyte sedimentation rate, $H A Q-D I$ Health Assessment Questionnaire-Disability Index, $N / A$ not assessed, $S D$ standard deviation, $S E$ standard error

a Non-responder imputation data at week 24 and observed data at week 52, $n$ (\%)

b Mixed-effect model repeated measures (MMRM) \pm SE data at week 24 and observed data $\pm S D$ at week 52

${ }^{*} P<0.05$ for secukinumab vs placebo

\section{Efficacy}

\section{Primary Efficacy Endpoint}

The primary endpoint was met by both the secukinumab groups; $35.2 \%$ of patients in the $150 \mathrm{mg}$ group and $35.2 \%$ of patients in the $75 \mathrm{mg}$ group achieved ACR20, compared with $19.6 \%$ in the placebo group $(P=0.0009 ;$ Table 2 and Fig. 2). In both treatment groups, secukinumab groups had a rapid onset of action, and both groups demonstrated numerically higher ACR20 response rates than placebo at all time points up to week 24 , with a more pronounced difference over placebo after week 8 (Fig. 2).

\section{Secondary Efficacy Endpoints Included in the Pre-defined Hierarchical Testing Strategy}

The first secondary endpoint, HAQ-DI at week 24 , was not met by either secukinumab group, and consequently neither were the remaining secondary endpoints in the hierarchal analysis. For HAQ-DI score, LS mean changes from baseline at week 24 were -0.35 for both secukinumab groups, compared with -0.24 the placebo group (supplementary Fig. S2). Secukinumab (pooled $150 \mathrm{mg}$ and $75 \mathrm{mg}$ ) reduced numerically the progression of structural damage over 24 weeks; vdH-mTSS was numerically lower in the pooled secukinumab group compared with the placebo group (treatment comparison estimate $0.82 ; P=0.0673$, unadjusted). This did not achieve statistical significance in the testing hierarchy $(P=0.2009$, adjusted; Table 2). Mean changes in vdH-mTSS from baseline to week 24 were 0.56 and 1.10 in the secukinumab $150 \mathrm{mg}$ and $75 \mathrm{mg}$ groups, respectively, and 1.35 in the placebo group.

At week $24,71.6 \%$ and $66.7 \%$ of patients in the secukinumab $150 \mathrm{mg}$ and $75 \mathrm{mg}$ groups, respectively, had no radiographic disease progression 


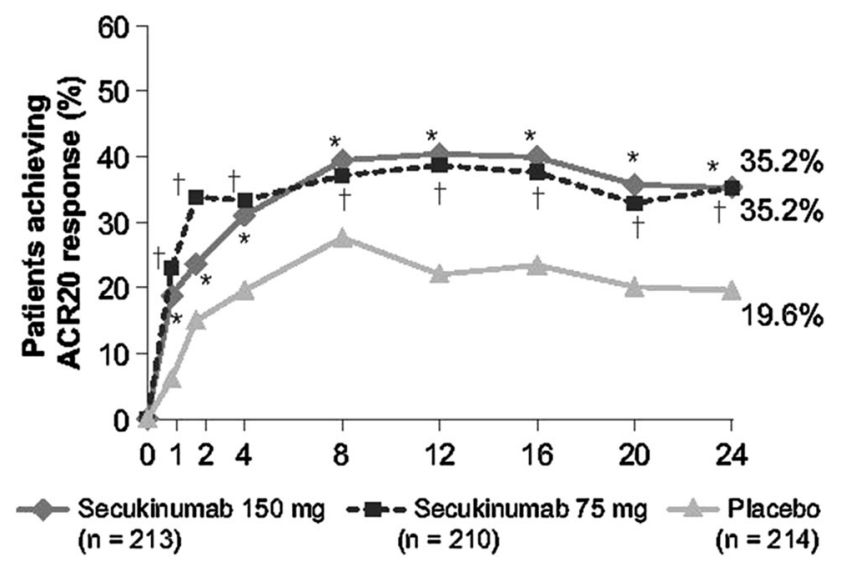

Fig. 2 ACR20 response using non-responder imputation over 24 weeks. Symbols indicate $P \leq 0.05$. ${ }^{*} P<0.05$ for secukinumab $150 \mathrm{mg}$ vs placebo; ${ }^{\dagger} P<0.05$ for secukinumab $75 \mathrm{mg}$ vs placebo. $P$ values are adjusted for multiplicity of testing for secukinumab $150 \mathrm{mg}$ and

(change $\leq 0$ from baseline in vdH-mTSS), both of which were numerically higher than the placebo group (59.0\%), as calculated by logistic regression with evaluable cases in the full analysis set.

MCR rate over the first 52 weeks was $0.9 \%$ [odds ratio (OR) 1.00; $P=1.000$, unadjusted] and $2.4 \%$ (OR 2.57; $P=0.2821$, unadjusted) for the secukinumab $150 \mathrm{mg}$ and $75 \mathrm{mg}$ groups, respectively, compared with $0.9 \%$ for the placebo group (Table 2).

\section{Other Secondary Efficacy Endpoints}

Observed ACR20 response rates for both secukinumab groups were stable from week 8 through week 104. Following a rapid onset of action, with a numerically higher proportion of patients in both secukinumab groups achieving the ACR20 response at week 1 compared with the placebo group. After the placebo controlled period the observed response rates for secukinumab were sustained.

Observed ACR50 responses at week 24 were numerically greater for both secukinumab groups [secukinumab $150 \mathrm{mg}, 17.6 \%$ (OR 2.69; $P=0.0031$, unadjusted) and secukinumab $75 \mathrm{mg}, \quad 16.0 \%$ (OR 3.03; $P=0.0008$, unadjusted)], compared with placebo (6.5\%; Table 2$)$.

Progression in vdH-mTSS over time was lower in patients treated with secukinumab $150 \mathrm{mg}$ than those treated with the $75 \mathrm{mg}$ dose. From secukinumab $75 \mathrm{mg}$ vs placebo at week 24. $A C R$ American College of Rheumatology, ACR20 improvement of $\geq 20 \%$ in ACR disease activity, $I V$ intravenous, $n$ number of subjects randomized

baseline to week 52 , mean changes in vdH-mTSS were 1.66 and 2.21 for the secukinumab $150 \mathrm{mg}$ and $75 \mathrm{mg}$ groups, respectively. From baseline to week 104, mean changes in vdH-mTSS were 3.83 and 5.58 for the secukinumab $150 \mathrm{mg}$ and $75 \mathrm{mg}$ groups, respectively.

\section{Safety}

\section{Short Term Placebo-Controlled Period (to Week 16)}

During the first 16 weeks, AEs were reported at a similar frequency across all treatment groups, with $54.5 \%$ and $58.1 \%$ of patients in the secukinumab $150 \mathrm{mg}$ and $75 \mathrm{mg}$ groups experiencing an $\mathrm{AE}$, respectively, compared with $57.0 \%$ of patients in the placebo group (Table 3 ).

The most frequently reported treatment-emergent AEs (TEAEs) by system organ class were infections and infestations $(23.5 \%$ and $28.6 \%$ in the secukinumab $150 \mathrm{mg}$ and $75 \mathrm{mg}$ groups, respectively, compared with $25.2 \%$ in the placebo group), gastrointestinal disorders (10.3\% and $11.4 \%$ compared with $16.8 \%)$, and musculoskeletal and connective tissue disorders $(9.4 \%$ and $8.6 \%$ compared with $15.0 \%$ ) (Table 3). Nasopharyngitis, pharyngitis, bronchitis, upper respiratory tract infection and headache were the most frequently reported TEAEs in the any secukinumab group up to 


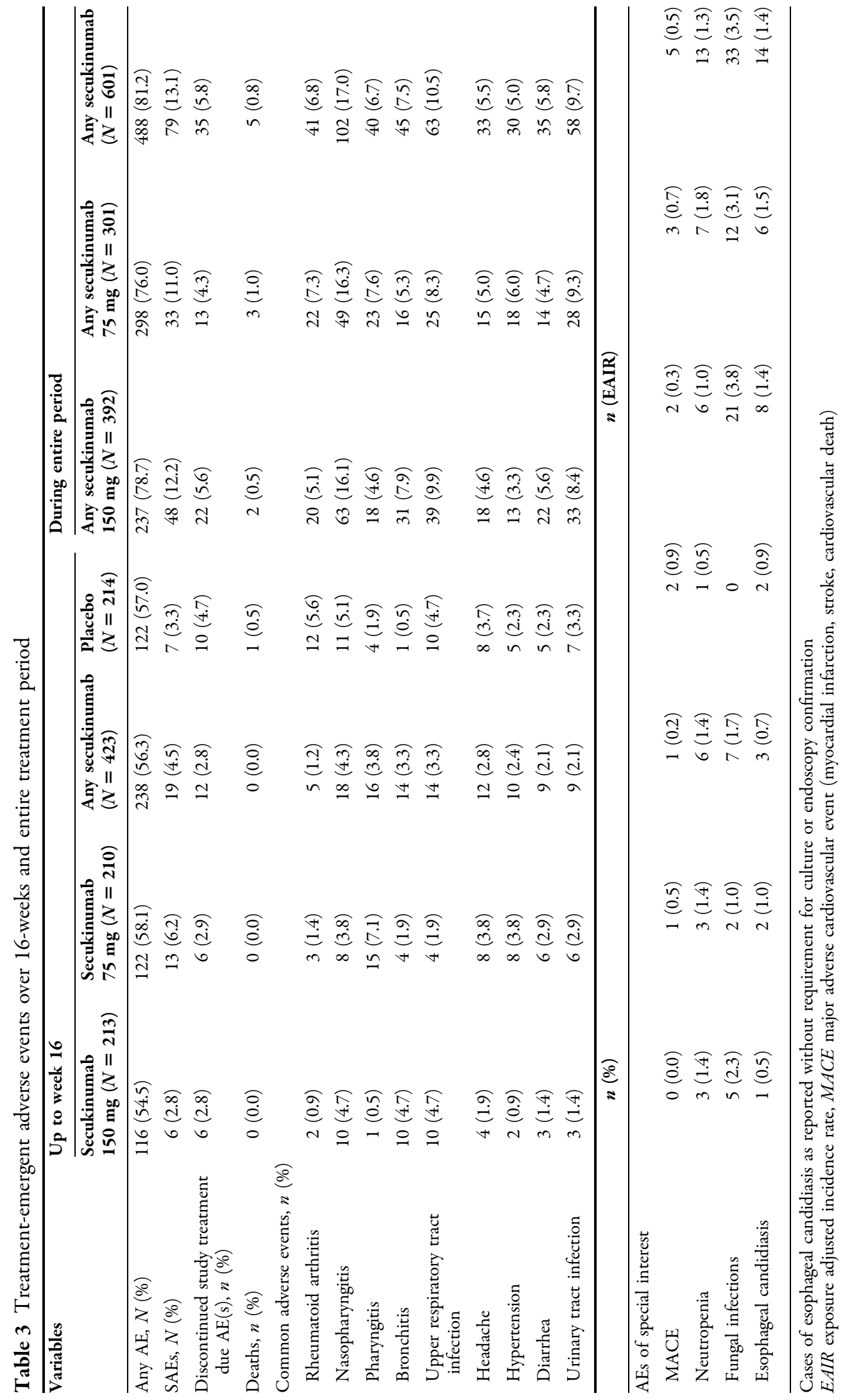


week 16. The majority of AEs reported up to week 16 in the any secukinumab dose group were mild $(31.4 \%)$ or moderate $(19.6 \%)$ in severity.

SAEs were reported for a higher percentage of patients in the any secukinumab group (4.5\%) compared with the placebo group (3.7\%). Infections and infestations qualifying as SAEs were reported by $5(1.9 \%)$ patients in the any secukinumab group compared with three patients $(0.5 \%)$ in the placebo group. Gastrointestinal disorders were reported as SAEs by three patients $(1.4 \%)$ in the secukinumab 75 group only. There were no reports of IBD. There were no clinically meaningful differences in the incidence of SAEs between the two secukinumab groups.

Lower proportions of patients in the any secukinumab dose group (2.8\%) had TEAEs leading to discontinuation from study treatment compared with the placebo group (4.7\%), which was mainly driven by the higher incidence of patients discontinuing treatment due to RA in the placebo group $(1.4 \%$ and $0.2 \%$, respectively).

In the placebo-controlled period up to week 16 , one death was reported; a patient in the placebo group who suffered cardiopulmonary failure, with pneumonia as a contributing factor.

\section{Entire Treatment Period}

The incidence of AEs during the entire treatment period was comparable within the two secukinumab groups $(76.0 \%$ and $78.7 \%$ in the any secukinumab $150 \mathrm{mg}$ and $75 \mathrm{mg}$ groups, respectively). The most common reason for the discontinuation was study discontinuation by sponsor $(25.4 \%$ and $22.4 \%$ in the any secukinumab $150 \mathrm{mg}$ and $75 \mathrm{mg}$ groups, respectively) followed by lack of efficacy (13.1\% and 19.5\%, respectively; supplementary Fig. S1).

Similar to the first 16 weeks of the study, AEs over the entire treatment period in the any secukinumab group were reported most frequently in the SOCs infections and infestations (55.6\%), musculoskeletal and connective tissue disorders (27.3\%), and gastrointestinal disorders (26.5\%). No dose dependency in AEs in any SOC was observed for secukinumab. Of TEAEs by preferred term in the any secukinumab group, nasopharyngitis, upper respiratory tract infection, urinary tract infection, bronchitis and RA were the most frequently reported (Table 3). There were no clinically meaningful differences in the incidence of AEs between the two secukinumab regimens. The majority of AEs reported in the any secukinumab dose group during the entire treatment period were mild $(35.8 \%)$ or moderate $(33.9 \%)$ in severity.

SAEs were reported for similar percentages of patients in the any secukinumab $150 \mathrm{mg}$ group $(12.2 \%)$ and the any secukinumab $75 \mathrm{mg}$ group (11.0\%). The two most common SAEs in the any secukinumab group during the entire treatment period were infections and infestations $[n=30$, incidence rate (IR) 3.1 per 100 patient years] and musculoskeletal and connective tissue disorders ( $n=15$, IR 1.5 per 100 patient years). There were no clinically meaningful differences in the incidence of SAEs between the two secukinumab groups.

Similar proportions of patients in the any secukinumab $150 \mathrm{mg}$ and $75 \mathrm{mg}$ groups $(5.6 \%$ and $4.3 \%$, respectively) discontinued treatment due to TEAEs (Table 3 ). There were no clinically meaningful differences in the proportions of patients with potential compound- and class-related risks based on AEs in both secukinumab groups.

The exposure-adjusted incidence rate (EAIR) of adjudicated major adverse cardiovascular events (MACE) in the any secukinumab group was 0.5 per 100 patient years. The EAIR for neutropenia in the any secukinumab group was 1.3 per 100 patient years. The EAIR for fungal infections in the any secukinumab group was 3.5 per 100 patient years.

Treatment emergent anti-drug antibodies (ADAs; developing on secukinumab treatment in patients negative at baseline) were detected for 38 patients. Neutralizing antibodies were not detected in any patients. Of the 38 patients with treatment emergent ADAs, 28 had detectable ADAs at single time points, while ADAs were detectable at more than one time point in only 10 patients.

Five deaths occurred after week 16; two in the any secukinumab $150 \mathrm{mg}$ group (due to sepsis and myocardial infarction), and three in 
the any secukinumab $75 \mathrm{mg}$ group (one due to acute myocardial infarction, one due to interstitial lung disease, and one of unknown cause). Over the entire treatment period, a total of 6 deaths were reported: 2 in the secukinumab $150 \mathrm{mg}$ group, 3 in the any secukinumab $75 \mathrm{mg}$ group, and 1 in the placebo group.

\section{DISCUSSION}

The treatment of RA continues to evolve and the potential role of IL-17 inhibition in the management of this disease remains an important issue. This phase 3 trial presents the only formal study of the effect of IL-17A inhibition on structural progression in patients with RA. Based on pre-defined hierarchical testing the primary endpoint was met by both the $150 \mathrm{mg}$ and $75 \mathrm{mg}$ secukinumab dose groups, indicating a statistically superior treatment effect over placebo. However, the main secondary objective (HAQ-DI at week 24) was not met for either secukinumab dose. A numerical reduction in radiographic progression was observed for the pooled secukinumab doses vs placebo in the placebo-controlled period of 24 weeks, but fell short of meeting statistical significance as pre-defined in the hierarchical testing. The protocol mandated escape of placebo patients to secukinumab after week 16 , and more than half the placebo patients switched to secukinumab at that time. This means that there was only a very short period during which radiographic progression on placebo could be captured given this placebo-controlled trial design.

Results from the phase 3 NURTURE trial, that directly compared secukinumab with abatacept in RA [19], as well as indirect comparisons of the efficacy from this trial with the efficacy of biologics approved for use in patients for whom TNF-inhibitors have failed, suggest that IL-17A inhibition offers no additional benefit to RA patients with inadequate response to TNF-inhibitors over currently approved therapies $[20,21]$. These findings led to a decision to discontinue the present trial, which bore influence on discontinuation rates in the core part of this trial (up to week 104), meaning that no patient completed the long-term extension. Of the 637 patients randomized, only 237 (37.2\%) completed 104 weeks of treatment. The most frequent reasons for study discontinuation were termination by sponsor $(23.1 \%)$ and lack of efficacy (16.6\%). Therefore, any conclusions, in particular on the longer-term efficacy outcomes, are very limited.

Safety data from this trial confirmed the safety profile of secukinumab as seen in the phase 3 trials in psoriasis [10], PsA [12] and AS [13]. The overall safety profiles of the secukinumab $150 \mathrm{mg}$ and secukinumab $75 \mathrm{mg}$ dose groups in this study were similar, with nasopharyngitis, upper respiratory tract infection, urinary tract infection, bronchitis and RA being most frequently reported TEAEs with secukinumab during entire treatment period. EAIRs for MACE [22] and deaths [23] are comparable to those observed for other biologics in patients with RA.

\section{CONCLUSIONS}

In summary this phase 3 trial is the only study of IL-17A inhibition on structural progression in RA. While there may have been a numerical trend for inhibition of structural progression the trial was hampered by high discontinuation rates and a very short placebo period. In contrast to the good efficacy of IL-17A inhibition seen in psoriasis, PsA and AS, secukinumab is of lesser benefit in RA patients for whom TNF-inhibitor therapy has failed. Given that multiple biologics with good efficacy are already available to these patients, further development of secukinumab for RA patients was not pursued.

\section{ACKNOWLEDGEMENTS}

The authors would like to thank the patients and the investigators who participated in the study. The study was sponsored by Novartis Pharma AG, Basel, Switzerland. Article processing charges were funded by Novartis Pharma AG, Basel, Switzerland. All authors had full access to all of the data in this study and take complete responsibility for the integrity of the 
data and accuracy of the data analysis. All named authors contributed significantly and meet the International Committee of Medical Journal Editors (ICMJE) criteria for authorship for this manuscript, take responsibility for the integrity of the work as a whole, and have given final approval to the version to be published. We would like to thank John Gallagher, medical consultant for Novartis Pharma AG, Basel, Switzerland, for editorial support, and Zailong Wang, a former employee of Novartis Pharmaceuticals Corporation, East Hanover, NJ, USA, for statistical support. Manuscript writing support, as requested by the authors, was provided by Sebastian Reynolds (Novartis Ireland Limited, Ireland) and Vasundhara Pathak (former employee of Novartis Healthcare Pvt. Ltd., India).

Disclosures.. H. Tahir has been on advisory boards for AbbVie, Eli -Lilly, MSD, Novartis, and has received education grants from AbbVie, Novartis, Pfizer. A. Deodhar has received research grants from Amgen, Eli Lilly, GlaxoSmithKline, Janssen, Novartis, Pfizer, UCB and has been on the advisory boards of Eli Lilly, GlaxoSmithKline, Janssen, Novartis, Pfizer, UCB. M. Genovese has received grants/contracts from Abbvie, Lilly, Novartis, UCB, and has received consultancy fees from Abbvie, Lilly, Novartis, UCB. T. Takeuchi has received grants from AbbVie GK, Asahikasei Pharma Corp., Astellas Pharma Inc., AYUMI Pharmaceutical Corporation, Bristol-Myers K.K., Chugai Pharmaceutical Co. Ltd, Daiichi Sankyo Co. Ltd, Eisai Co. Ltd, Takeda Pharmaceutical Co. Ltd, Taisho Toyama Pharmaceutical Co. Ltd, Teijin Pharma Ltd, and has received speaking fees from AbbVie GK, Astellas Pharma Inc., Bristol-Myers K.K., Celtrion, Chugai Pharmaceutical Co. Ltd, Diaichi Sankyo Co. Ltd, Eisai Co. Ltd, Janssen Pharmaceutical K.K., Mitsubishi Tanabe Pharma Co., Pfizer Japan Inc., Takeda Pharmaceutical Co. Ltd, and Nipponkayaku Co. Ltd, and has received consultancy fees from Abbivie GK, Asahi Kasei Medical K.K., Astellas Pharma Inc., Astra Zeneca K.K., Bristol-Myers K.K., Daiichi Sankyo Co. Ltd, Eli Lilly Japan K.K., Janssen Pharmaceutical K.K.,
Merck Serono Co. Ltd, Mitsubishi Tanabe Pharma Co., Nipponkayaku Co. Ltd, Novartis Pharma K.K., Pfizer Japan Inc., Takeda Pharmaceutical Co. Ltd. J. Aelion has received research grants from AbbVie, Amgen, Astra Zeneca, Bristol Myers Squibb, Celgene, Eli Lilly, Galapagos, Genentech, GlaxoSmithKline, Janssen, Merck, Mesoblast, Novartis, Novo Nordisk, Pfizer, Sanofi- Aventis, Takeda, UCB, and has been on the advisory boards of AbbVie, Amgen, Celgene, Eli Lilly, Janssen, UCB. F. Van den Bosch has received speaker and/or consultancy fees from Abbvie, Bristol-Myers Squibb, Celgene, Janssen, Merck, Novartis, Pfizer and UCB. S. Haemmerle is an employee of Novartis. H.B. Richards is an employee of Novartis and is a Novartis Shareholder.

Compliance with Ethics Guidelines. All procedures followed were in accordance with the ethical standards of the responsible committee on human experimentation (institutional and national) and with the Helsinki Declaration of 1964, as revised in 2013. Informed consent was obtained from all patients for being included in the study.

Data Availability. The datasets generated during and/or analyzed during the current study are available from the corresponding author on reasonable request.

Open Access. This article is distributed under the terms of the Creative Commons Attribution-NonCommercial 4.0 International License (http://creativecommons.org/licenses/ by-nc/4.0/), which permits any noncommercial use, distribution, and reproduction in any medium, provided you give appropriate credit to the original author(s) and the source, provide a link to the Creative Commons license, and indicate if changes were made.

\section{REFERENCES}

1. McInnes IB, Schett G. The pathogenesis of rheumatoid arthritis. $\mathrm{N}$ Engl J Med. 2011;365(23):2205-19. 
2. Smolen JS, Aletaha D, McInnes IB. Rheumatoid arthritis. Lancet. 2016;388(10055):2023-38.

3. Cohen SB, Emery P, Greenwald MW, Dougados M, Furie RA, Genovese MC, et al. Rituximab for rheumatoid arthritis refractory to anti-tumor necrosis factor therapy: Results of a multicenter, randomized, double-blind, placebo-controlled, phase III trial evaluating primary efficacy and safety at twenty-four weeks. Arthritis Rheum. 2006;54(9):2793-806.

4. Rituximab: Highlights of prescribing information. 2017. http://www.accessdata.fda.gov/drugsatfda docs/label/2010/103705s5311lbl.pdf (cited 12 July 2017).

5. Chabaud M, Page G, Miossec P. Enhancing effect of IL-1, IL-17, and TNF-alpha on macrophage inflammatory protein-3alpha production in rheumatoid arthritis: regulation by soluble receptors and Th2 cytokines. J Immunol. 2001;167(10):6015-20.

6. Lubberts E, Koenders MI, van den Berg WB. The role of T-cell interleukin-17 in conducting destructive arthritis: lessons from animal models. Arthritis Res Ther. 2005;7(1):29-37.

7. Stamp LK, James MJ, Cleland LG. Interleukin-17: the missing link between T-cell accumulation and effector cell actions in rheumatoid arthritis? Immunol Cell Biol. 2004;82(1):1-9.

8. Witowski J, Książek K, Jörres A. Interleukin-17: a mediator of inflammatory responses. Cell Mol Life Sci. 2004;61(5):567-79.

9. Moseley TA, Haudenschild DR, Rose L, Reddi AH. Interleukin-17 family and IL-17 receptors. Cytokine Growth Factor Rev. 2003;14(2):155-74.

10. Langley RG, Elewski BE, Lebwohl M, Reich K, Griffiths CE, Papp K, et al. Secukinumab in plaque psoriasis-results of two phase 3 trials. N Engl J Med. 2014;371(4):326-38.

11. McInnes IB, Mease PJ, Kirkham B, Kavanaugh A, Ritchlin CT, Rahman P, et al. Secukinumab, a human anti-interleukin-17A monoclonal antibody, in patients with psoriatic arthritis (FUTURE 2): a randomised, double-blind, placebo-controlled, phase 3 trial. Lancet. 2015;386(9999):1137-46.

12. Mease PJ, McInnes IB, Kirkham B, Kavanaugh A, Rahman P, van der Heijde D, et al. Secukinumab inhibition of interleukin-17A in patients with psoriatic arthritis. $\mathrm{N}$ Engl J Med. 2015;373(14):1329-39.

13. Baeten D, Sieper J, Braun J, Baraliakos X, Dougados M, Emery P, et al. Secukinumab, an interleukin-17A inhibitor, in ankylosing spondylitis. N Engl J Med. 2015;373(26):2534-48.

14. Cosentyx: Highlights of prescribing information. $2017 . \quad$ https://www.pharma.us.novartis.com/ product/pi/pdf/cosentyx.pdf (cited 12 July 2017).

15. Hueber W, Patel DD, Dryja T, Wright AM, Koroleva I, Bruin G, et al. Effects of AIN457, a fully human antibody to interleukin-17A, on psoriasis, rheumatoid arthritis, and uveitis. Sci Transl Med. 2010;2(52):52-72.

16. Tlustochowicz W, Rahman P, Seriolo B, Krammer G, Porter B, Widmer A, et al. Efficacy and safety of subcutaneous and intravenous loading dose regimens of secukinumab in patients with active rheumatoid arthritis: results from a randomized phase II study. J Rheumatol. 2016;43(3):495-503.

17. Genovese MC, Durez P, Richards HB, Supronik J, Dokoupilova E, Aelion JA, et al. One-year efficacy and safety results of secukinumab in patients with rheumatoid arthritis: phase II, dose-finding, double-blind, randomized, placebo-controlled study. J Rheumatol. 2014;41(3):414-21.

18. Genovese MC, Durez P, Richards HB, Supronik J, Dokoupilova E, Mazurov V, et al. Efficacy and safety of secukinumab in patients with rheumatoid arthritis: a phase II, dose-finding, double-blind, randomised, placebo controlled study. Ann Rheum Dis. 2013;72(6):863-9.

19. Blanco FJ, Möricke R, Dokoupilova E, Codding C, Neal J, Andersson M, Rohrer S, Richards H. Secukinumab in active rheumatoid arthritis: a phase III randomized, double-blind, active comparator- and placebo-controlled study. Arthritis Rheumatol. 2017;69(6):1144-53.

20. Breedveld FC, Weisman MH, Kavanaugh AF, Cohen SB, Pavelka K, van Vollenhoven R, et al. The PREMIER study: a multicenter, randomized, double-blind clinical trial of combination therapy with adalimumab plus methotrexate versus methotrexate alone or adalimumab alone in patients with early, aggressive rheumatoid arthritis who had not had previous methotrexate treatment. Arthritis Rheum. 2006;54(1):26-37.

21. Weinblatt ME, Kremer JM, Bankhurst AD, Bulpitt KJ, Fleischmann RM, Fox RI, et al. A trial of etanercept, a recombinant tumor necrosis factor receptor: Fc fusion protein, in patients with rheumatoid arthritis receiving methotrexate. $\mathrm{N}$ Engl J Med. 1999;340(4):253-9.

22. Zhang J, Xie F, Yun H, Chen L, Muntner P, Levitan $\mathrm{EB}$, et al. Comparative effects of biologics on cardiovascular risk among older patients with 
rheumatoid arthritis. Ann Rheum Dis. 2016;75:1813-8.

23. Burmester GR, Panaccione R, Gordon KB, McIlraith MJ, Lacerda AP. Adalimumab: long-term safety in
23458 patients from global clinical trials in rheumatoid arthritis, juvenile idiopathic arthritis, ankylosing spondylitis, psoriatic arthritis, psoriasis and Crohn's disease. Ann Rheum Dis. 2013;72(4):517-24. 